Supporting Information for

\title{
Influence of spatial distribution of cationic functional groups at nanoparticle surfaces on bacterial viability and membrane interactions
}

Yongqian Zhang ${ }^{\dagger}$, Natalie V. Hudson-Smith ${ }^{\ddagger}$, Seth D. Frand ${ }^{\perp}$, Meghan S. Cahill ${ }^{\ddagger}$, Larissa S. Davis ${ }^{\dagger}$, Z.

Vivian Feng ${ }^{\perp}$, Christy L. Haynes ${ }^{\ddagger}$, Robert J. Hamers ${ }^{\dagger}$

${ }^{\dagger}$ University of Wisconsin-Madison, Department of Chemistry, Madison, WI 53706, USA

*University of Minnesota twin cities, Department of Chemistry, Minneapolis,, MN 55455, USA

${ }^{\perp}$ Augsburg University, Department of Chemistry, Minneapolis, MN, 55454, USA

1. 11-trimethylammonium-1-undecene bromide synthesis and characterization ........ Page 2

2. Detailed conditions for functionalization of cationic surfaces on diamond NPs ..... Page 3-6

3. Hydrodynamic size and zeta potential characterization of cationic diamond NPs ...Page 6

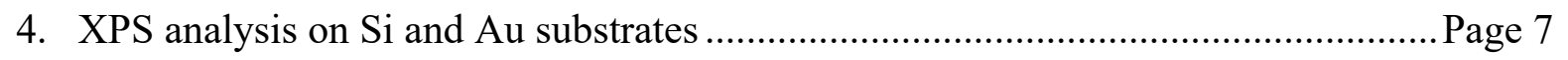

5. XPS quantification of amine-DNPs ……...................................................... Page 8

6. NMR spectra details of amine-functionalized DNPs ..............................................9age 9-10

7. Biological responses plot versus diamond NP concentration. ................................ Page 11

8. TEM micrographs of cationic-DNPs exposed $S$. oneidensis...................... Page 12-14

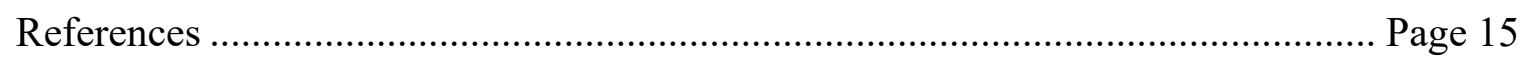




\section{SUPPLEMENTAL MATERIALS AND METHODS}

1. 11-trimethylammonium-1-undecene bromide synthesis and characterization. The synthesis of 11trimethylammonium-1-undecene bromide is adapted from the synthesis of 16mercaptohexadecyltrimethylammonium bromide $\quad$ (MTAB). ${ }^{1} \quad$ 11-trimethylammonium-1-undecene bromide was prepared by dissolving 11-bromo-1-undecene ( $4 \mathrm{~mL}, 95 \%$ purity) and ethanolic solution of trimethylamine $(4.2 \mathrm{M}, 30 \mathrm{~mL}, 31-35$ wt. $\%$ in ethanol $4.2 \mathrm{M}$, contains toluene as stabilizer) in $10 \mathrm{~mL}$ ethyl acetate. The resulting mixture was vigorously stirred under $\mathrm{N}_{2}$ for 4 days. The product was washed with ethyl acetate to remove excess trimethyl amine and purified using vacuum filtration, giving a yield of $76 \%$ of the starting materials. The product was stored dry inside a desiccator. The chemical structure of the 11-trimethylammonium-1-undecene bromide was confirmed by ${ }^{1} \mathrm{H}$ and ${ }^{13} \mathrm{C} \mathrm{NMR}$ shown below. ${ }^{1} \mathrm{H} \mathrm{NMR}\left(\mathrm{CDCl}_{3}\right.$, $500 \mathrm{MHz}) \delta: 5.78(\mathrm{ddt}, 1.0 \mathrm{H}), 4.95(\mathrm{~m}, 2.0 \mathrm{H}), 3.6(\mathrm{~m}, 2.2 \mathrm{H})$, $3.46(\mathrm{~s}, 9.1 \mathrm{H}), 2.02(\mathrm{~m}, 2.1 \mathrm{H}), 1.35-1.30(\mathrm{~m}, 14.7 \mathrm{H}) .{ }^{13} \mathrm{C}$ $\mathrm{NMR}\left(\mathrm{CDCl}_{3}, 500 \mathrm{MHz}\right) \delta: 138.7$ (1 C), 114.2 (2 C), 66.8 (1 C), 53.4 (3 C), 33.7 (1 C), 29.3 - 23.4 (7 C). High-resolution electrospray ionization mass spectrometry for $\mathrm{C}_{14} \mathrm{H}_{30} \mathrm{~N}\left(\mathrm{M}^{+}\right)$ yielded a mass-to-charge ratio $\mathrm{m} / \mathrm{z}=212.2373$, nearly identical to the expected value of $m / z=212.2373(<0.1 \mathrm{ppm})$.

a)
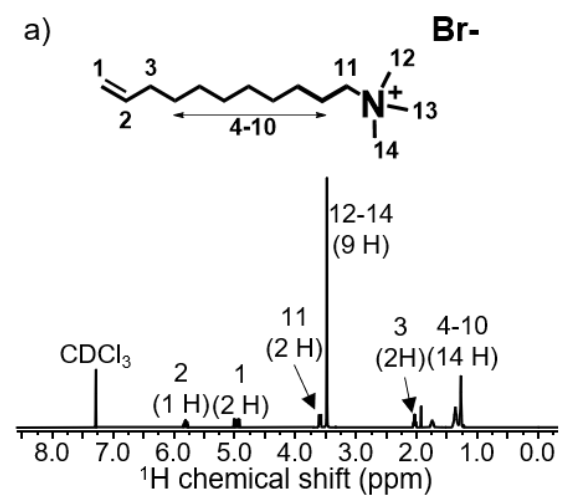

b)

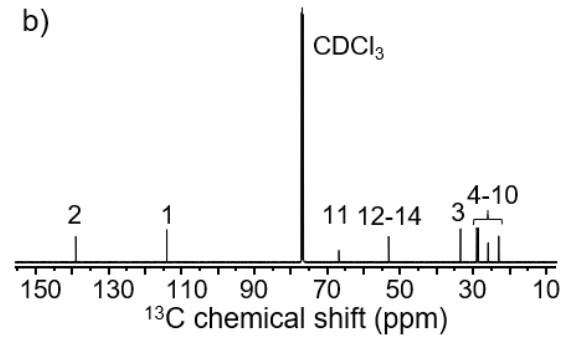

Fig. S1. (a) ${ }^{1} \mathrm{H}$ NMR and (b) ${ }^{13} \mathrm{C}$ NMR of the 11trimethylammonium-1-undecene bromide ligand in $\mathrm{CDCl}_{3}$. 


\section{Detailed conditions for functionalization of cationic surfaces on diamond NPs.}

- For C3 quaternary amine-DNPs $\left(\mathrm{C} 3-\mathrm{N}\left(\mathrm{CH}_{3}\right)_{3}{ }^{+}-\mathrm{DNPs}\right)$ : The reaction mix contains $50 \mathrm{mg}$ of the hydrogen-functionalized DNPs, $50 \mathrm{mg}$ benzoyl peroxide, and $700 \mathrm{mg}$ of the allyl trimethylammonium bromide in $5 \mathrm{~mL}$ anhydrous benzene (99.8\%) (anhydrous chloroform works too).

- For C3 primary amine-DNPs $\left(C 3-\mathrm{NH}_{3}{ }^{+}-\mathrm{DNPs}\right)$ : The reaction mix contains $50 \mathrm{mg}$ of the hydrogenfunctionalized DNPs, $50 \mathrm{mg}$ benzoyl peroxide and $700 \mathrm{mg}$ of the allyl tert-butyl carbamate (98\%, SigmaAldrich) in $5 \mathrm{~mL}$ anhydrous chloroform ( $\geqq 99 \%$, contains $0.5-1.0 \%$ ethanol as stabilizer). The tert-butyl carbamate (Boc-amine) functionalized DNP surfaces were dissolved in solvent and purified by centrifugation. This process was repeated three time. The purified product was then dissolved in a solution of and methylene chloride $(1: 1, \mathrm{v}: \mathrm{v})$ for $1 \mathrm{~h}$ at room temperature to allow the Boc-amine protective group back to primary amine group ${ }^{2}$. The surface structures of both Boc-amine-DNPs and C3 primary amineDNPs are confirmed by ${ }^{1} \mathrm{H}$ NMR and are shown in Figure S2b.

a)

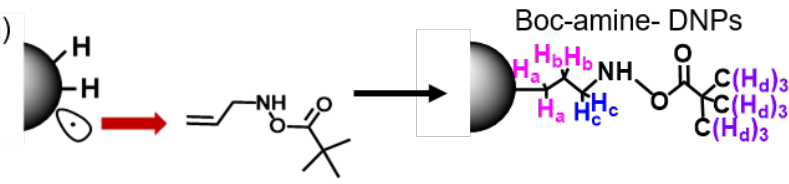

C3 primary amine- DNPs
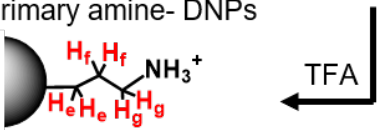

b) C3 primary amine- DNPS

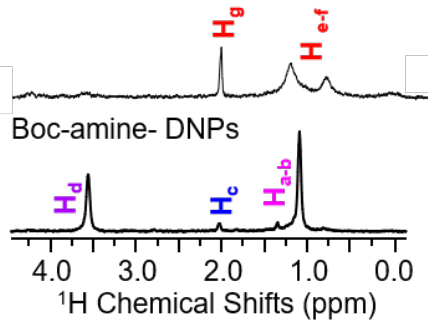

Fig. S2. (a) Two- step functionalization scheme of C3 primary amineDNPs. (b) ${ }^{1} \mathrm{H}$ NMR spectra of the $\mathrm{C} 3$ primary amine-DNPs (top) and tertbutyl carbamate functionalized DNPs (Boc-amine DNPs, bottom) in $\mathrm{D}_{2} \mathrm{O}$. 
- For C11 quaternary amine-DNPs $\left(C 11-N_{(}\left(\mathrm{CH}_{3}\right)_{3}{ }^{+}-\mathrm{DNPS}\right)$ : The reaction mix contains $50 \mathrm{mg}$ of the hydrogen-functionalized DNPs, $50 \mathrm{mg}$ benzoyl peroxide and $500 \mathrm{mg}$ of the C11 trimethylammonium-1undecene bromide in $5 \mathrm{~mL}$ anhydrous benzene (99.8\%).

- For TEPA-DNPs: The reaction mix contains $50 \mathrm{mg}$ of the hydrogen-functionalized DNPs, $50 \mathrm{mg}$ benzoyl peroxide and $200 \mu \mathrm{L}$ of the 5-hexenoic acid (98\%) in $3 \mathrm{~mL}$ anhydrous benzene (99.8\%). The carboxyl functionalized DNPs (COOH- DNPs) were dissolved in solvent and purified by centrifugation. This process was repeated three time. The purified $\mathrm{COOH}-\mathrm{DNPs}$ pellet was re-suspended into 0.1 M MES buffer solution to archive a final concentration DNP concentration of $0.5 \mathrm{nM}$ DNP. To every $1 \mathrm{~mL}$ of the COOH-DNPs solution, $100 \mu \mathrm{L}$ of TEPA solution $(0.01 \mathrm{mg} / \mathrm{mL}$ TEPA in $10 \mathrm{mM}$ MES buffer) was added, mixed and stirred for 15-20 min. To this solution, aqueous solutions of coupling reagents EDC $(1 \mathrm{mg} / \mathrm{mL})$ and sulfo-NHS $(2 \mathrm{mg} / \mathrm{mL})$ were introduced simultaneously. The reaction mixture was stirred at room temperature overnight to allow the primary amine group from TEPA molecules to attach to the carboxyl surfaces. The $\mathrm{pH}$ of the final solution was controlled to be around 6-7. The TEPA-DNPs were purified by centrifugation (3 times, $10000 \mathrm{rpm}, 10-20 \mathrm{~min}$ ) and redispersed into nanopure water. The zeta potential of the purified COOH- DNPs was $-11.5 \mathrm{mV} \pm 0.2 \mathrm{mV}$ and that of the purified TEPA-DNPs was $46.4 \pm$

a)
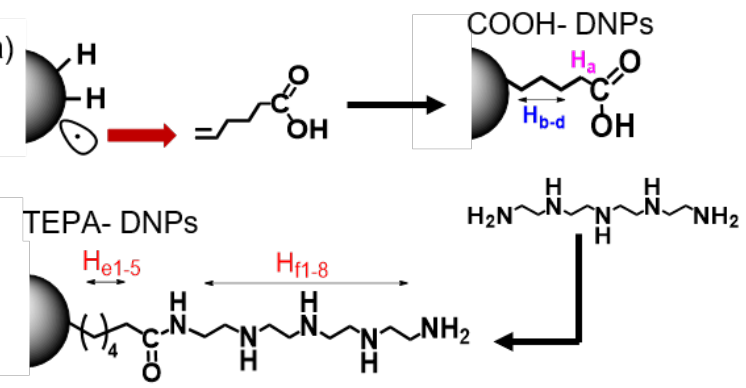

b) $\mathrm{COOH}$ - DNPS

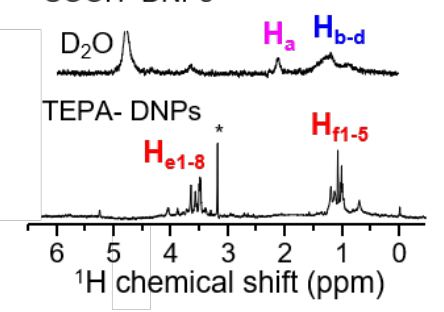

Fig. S3. (a) Two- step functionalization scheme of TEPA-DNPs. (b) ${ }^{1} \mathrm{H}$ NMR spectra of the COOH- DNPs (top) and TEPA functionalized DNPs (bottom) in $\mathrm{D}_{2} \mathrm{O}$. 
$3.2 \mathrm{mV}$. The surface structures of both COOH-DNPs and TEPA-DNPs are confirmed by ${ }^{1} \mathrm{H}$ NMR and are shown in Figure S3b.

- For PAH-DNPs: The reaction mix contains $50 \mathrm{mg}$ of the hydrogen-functionalized DNPs, $50 \mathrm{mg}$ benzoyl peroxide and $200 \mu \mathrm{L}$ of the 5-hexenoic acid (98\%) in $3 \mathrm{~mL}$ anhydrous benzene (99.8\%). The carboxyl functionalized DNPs (COOH-DNPs) were dissolved in solvent and purified by centrifugation. This process was repeated three time. The purified $\mathrm{COOH}-\mathrm{DNPs}$ pellet was re-suspended into $0.1 \mathrm{M}$ MES buffer solution to archive a final concentration DNP concentration of $0.5 \mathrm{nM}$ DNP. To every $1 \mathrm{~mL}$ of the COOH-DNPs solution, $100 \mu \mathrm{L}$ of PAH solution $(0.01 \mathrm{mg} / \mathrm{mL}$ PAH in $10 \mathrm{mM}$ MES buffer) was added, mixed and stirred for 15-20 min. To this solution, aqueous solutions of coupling reagents EDC ( $1 \mathrm{mg} / \mathrm{mL})$ and sulfo-NHS $(2 \mathrm{mg} / \mathrm{mL})$ were introduced simultaneously. The reaction mixture was stirred at room temperature overnight to allow the primary amine group from PAH molecules to attach to the carboxyl surfaces. The $\mathrm{pH}$ of the final solution was controlled to be around 6-7. The PAH-DNPs were purified by centrifugation (3 times, $10000 \mathrm{rpm}, 10-20 \mathrm{~min}$ ) and redispersed into nanopure water. The zeta potential of the purified COOH-DNPs was $-11.5 \mathrm{mV} \pm 0.2 \mathrm{mV}$ and that of the purified PAH-DNPs was $61.6 \pm 2.2$

a)
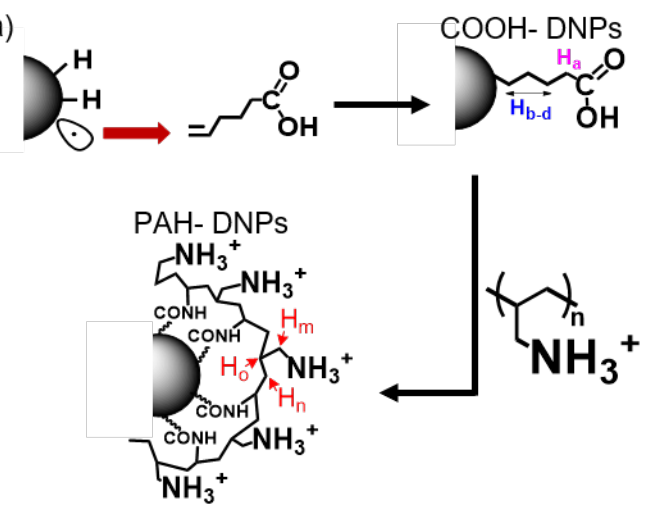

b)

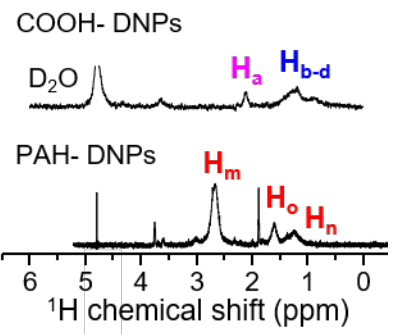

Fig. S4. (a) Two- step functionalization scheme of PAH-DNPs. (b) ${ }^{1} \mathrm{H}$ NMR spectra of the COOH-DNPs (top) and PAH functionalized DNPs (bottom) in $\mathrm{D}_{2} \mathrm{O}$. 
$\mathrm{mV}$. The surface structures of both COOH-DNPs and PAH- DNPs are confirmed by ${ }^{1} \mathrm{H}$ NMR and are shown in Figure S4b.

\section{Hydrodynamic size and zeta potential characterization of cationic diamond NPs. The}

hydrodynamic diameters were measured at $298 \mathrm{~K}$ with a scattering angle of $173^{\circ}$. All measurements were obtained from five separate measurements, each with ten analytical replicates. The zeta potential measurements were obtained from 10 separate measurements, each with ten analytical replicates.

Table. S1. A summary of the hydrodynamic size and zeta potential of amine-functionalized samples in nanopure water.

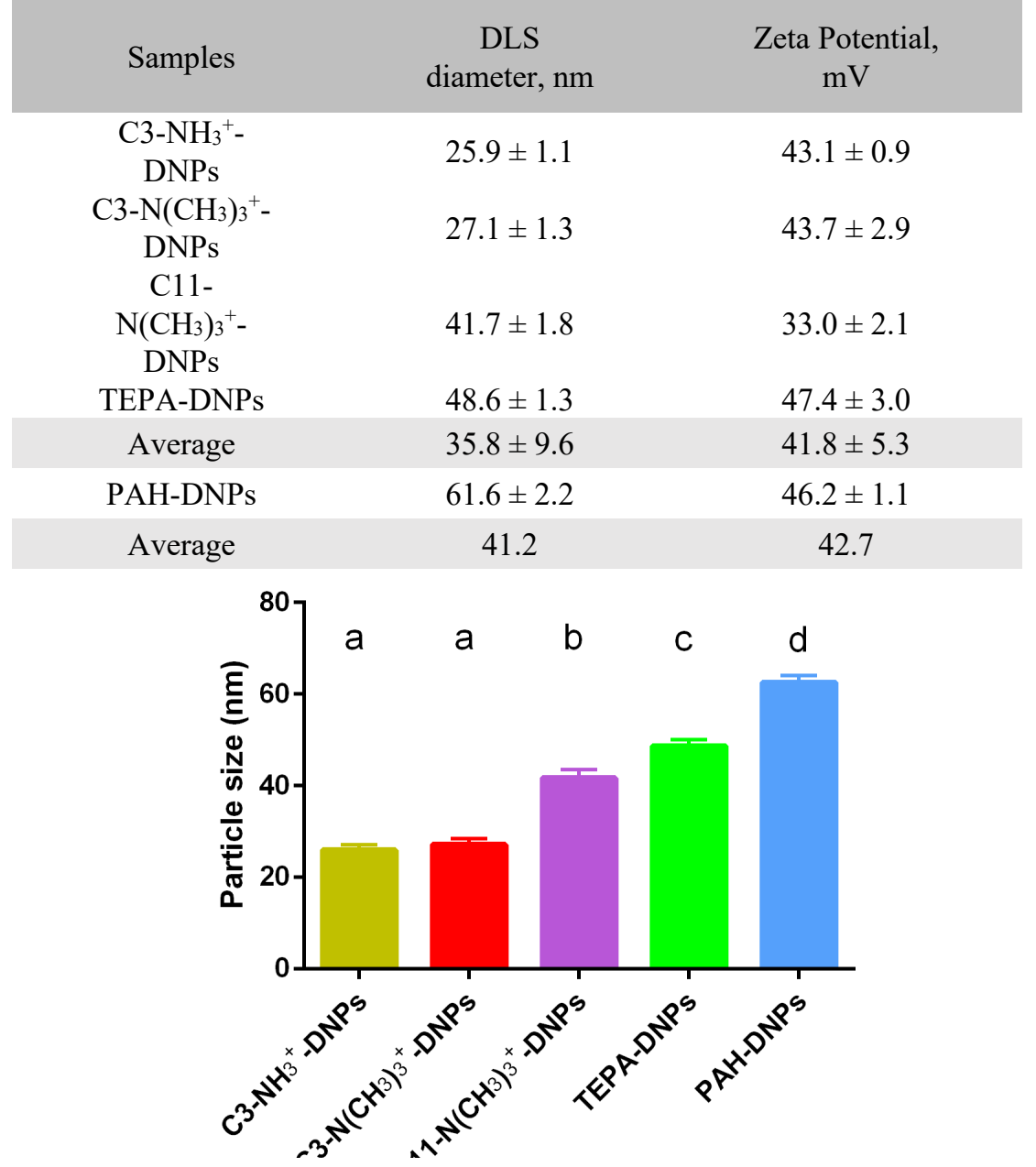

Fig. S5. Hydrodynamic diameter values of all cationic DNPs in nanopure water ( $\mathrm{n}>5$ from technical replicates). Label a, b, c, d denote statistical differences among measurements using one-way ANOVA Tukey's multiple comparison test $(p<0.05)$. All error bars represent the standard deviation. 
4. XPS analysis on Si and Au substrates. Measurements that were done on doped Si wafers were consistent with those on gold wafers.

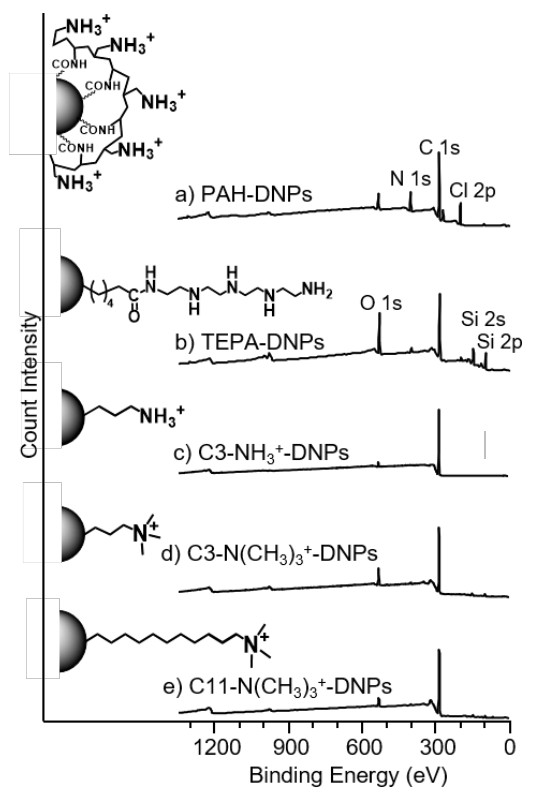

Fig. S6. XPS survey spectra of a) PAH-DNPs, b) TEPA-DNPs, c) C3-NH ${ }_{3}{ }^{+}-\mathrm{DNPs}$, d) C3-N( $\left(\mathrm{CH}_{3}\right)_{3}{ }^{+}-\mathrm{DNPs}$ and e) $\mathrm{C} 11-\mathrm{N}\left(\mathrm{CH}_{3}\right)_{3}{ }^{+}$-DNPs on doped silicon wafers (B-doped, $0.1-1 \mathrm{ohm} \cdot \mathrm{cm}$ resistivity, Electro-Optic Materials).

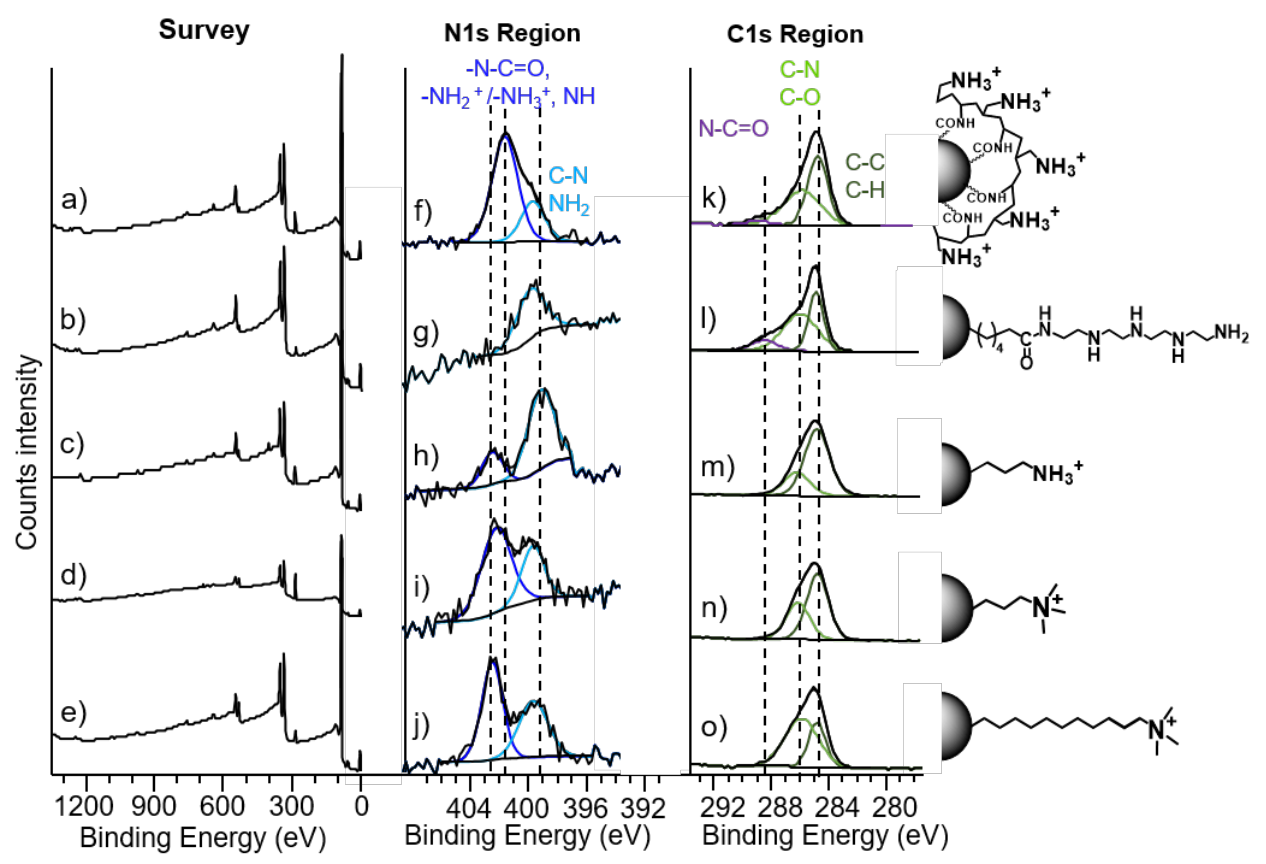

Fig. S7. XPS survey spectra (a-e), N(1s) region spectra (f-j) and C(1s) region spectra (k-o) of PAH-DNPs, TEPA-DNPs, d) C3- $\mathrm{NH}_{3}{ }^{+}-\mathrm{DNPs}$, e) $\mathrm{C} 3-\mathrm{N}\left(\mathrm{CH}_{3}\right)_{3}{ }^{+}$-DNPs and f) $\mathrm{C} 11-\mathrm{N}\left(\mathrm{CH}_{3}\right)_{3}{ }^{+}$-DNPs on gold coated silicon wafer (50 $\mathrm{nm} \mathrm{Au}$ on 500um P-type). 
5. XPS quantification of amine-DNPs. The densities of surface atom of functionalized DNPs were calculated for all samples using eq 1 .

$$
N(1 s)=\frac{A_{\text {surface }}}{A_{\text {core }}} \frac{S_{\text {core }}}{S_{\text {surface }}} \cdot \rho \cdot I M F P_{\text {surface,diamond }} \cdot \operatorname{Cos}\left(45^{\circ}\right)
$$

Where $A$ is the peak area, $S$ is the relative sensitivity factor, $\rho$ is the number density of carbon atoms in diamond; and IMFP is the inelastic mean free path of surface atom photoelectrons in core material (either $\mathrm{C} 1 \mathrm{~s}$ or diamond). ${ }^{3}$ The $\cos \theta$ counts for the angle (with respect to surface normal) electrons were collected. Atom densities were calculated from $A_{\text {surface }} / A_{\text {core }} u$ sing eq 1; the corrected atom densities are calculated using the numeric curvature correction method previously reported from our group ${ }^{4}$. All samples were first cleaned with ethanol, followed with 10 mins sonication. The process was then repeated twice with water. The cleaned samples were dried under nitrogen stream before the XPS measurements. Table. S2 summarizes the results for all samples.

Table. S2. Quantitative analysis of molecular densities of all amine modified DNPs.

$\begin{array}{ccc}\text { Material surfaces } & \begin{array}{c}\text { Atomic area density } \\ \text { atoms } \mathrm{nm}^{-2}\end{array} & \begin{array}{c}\text { Molecules area density } \\ \text { molecules } \mathrm{nm}^{-2}\end{array} \\ \mathrm{C} 3-\mathrm{NH}_{3}{ }^{+}-\mathrm{DNPs} & 0.6 \pm 0.1 & 0.6 \pm 0.1 \\ \mathrm{C} 3-\mathrm{N}\left(\mathrm{CH}_{3}\right)_{3}{ }^{+}-\mathrm{DNPs} & 0.8 \pm 0.2 & 0.8 \pm 0.2 \\ \mathrm{C} 11-\mathrm{N}\left(\mathrm{CH}_{3}\right)_{3}{ }^{+}-\mathrm{DNPs} & 0.5 \pm 0.02 & 0.5 \pm 0.02 \\ \mathrm{TEPA}-\mathrm{DNPs} & 5.0 \pm 0.7 & 1.0 \pm 0.1 \\ \text { PAH-DNPs } & 1.3 \pm 0.06 & - \\ \text { Average value } & - & 0.7 \pm 0.2\end{array}$




\section{NMR spectra interpretation of amine-functionalized DNPs.}

C3- $\mathrm{NH}_{3}{ }^{+}-$DNPs: For C3-NH${ }_{3}{ }^{+}-\mathrm{DNPs}$ (Fig.3a), three peaks at $0.80 \mathrm{ppm}, 1.20 \mathrm{ppm}$ and 2.03 ppm are shown. The peaks at $0.80 \mathrm{ppm}$ and $1.20 \mathrm{ppm}$ are characteristic of saturated $\mathrm{C}-\mathrm{H}$ regions ${ }^{5}$; we attribute these to the protons that are labeled in Fig. $3 \mathrm{a}$ as a and $\mathrm{b}$. We attribute the peak at 2.03 ppm to the proton on the $\mathrm{C}$ atom adjacent to the primary amine head group ${ }^{6}$ (labeled as c).

C3-N(CH$)_{3}{ }^{+}$-DNPs: For $\mathrm{C} 3-\mathrm{N}\left(\mathrm{CH}_{3}\right)_{3}{ }^{+}$-DNPs (Fig. 3b), our peaks associated with the propyl trimethylamine molecule are observed at $0.07 \mathrm{ppm}, 0.15 \mathrm{ppm}, 3.10 \mathrm{ppm}$ and $3.91 \mathrm{ppm}$. Based on prior studies of similar compounds, we attribute the peaks at $0.07 \mathrm{ppm}$ and $0.15 \mathrm{ppm}$ to the saturated $\mathrm{C}-\mathrm{H}$ protons from the hydrocarbon chain on propyl trimethylamine (labeled as $d$ and e). The chemical shifts of the trimethylammonium head group are well established and distinctive. The $9 \mathrm{H}$ on the trimethylammonium head group has a chemical shift approximately at $3 \mathrm{ppm}^{7}$ and the $2 \mathrm{H}$ on the carbon that is adjacent to the trimethylammonium head group has a chemical shift at approximately $4.0 \mathrm{ppm}^{7-8}$. Therefore, we assigned the peak at $3.1 \mathrm{ppm}$ to the 9 protons on the trimethyl head groups (labeled as g); and the peak at $3.91 \mathrm{ppm}$ to the 2 protons on the carbon adjacent to the trimethylamine head group (labeled ass f).

C11-N(CH$)_{3}{ }^{+}-$DNPs: The assignments for the C11-N( $\left(\mathrm{CH}_{3}\right)_{3}{ }^{+}$-DNPs (Fig. 3c) are similar to the ones of the C3 qa-DNPs, due to their structural similarity. We assign the peak at $3.11 \mathrm{ppm}$ as the $9 \mathrm{H}$ from the three $\mathrm{CH}_{3}$ on the trimethylamine head group (labeled as $\mathrm{j}$ ), and the peak at $3.35 \mathrm{ppm}$ arises from the $2 \mathrm{H}$ from the $\mathrm{CH}_{2}$ adjacent to the trimethylamine head group (labeled as i). The peaks at approximately 1.33 ppm are representative of aliphatic chains for similar compounds ${ }^{7,9}$ and therefore were assigned as the ten saturated $\mathrm{CH}_{2}$ protons (labeled as $\mathrm{h}_{1-10}$ ) along the main chain that have similar chemical shifts. 
TEPA-DNPs: TEPA-functionalized DNPs (Fig. 3d) shows two groups of overlapped peaks in regions of $1.02 \mathrm{ppm}-1.21 \mathrm{ppm}$ and $3.46 \mathrm{ppm}-3.66 \mathrm{ppm}$. The first group of overlapped peaks at $1.02 \mathrm{ppm}, 1.07$ ppm, $1.08 \mathrm{ppm}, 1.14 \mathrm{ppm}$ and $1.21 \mathrm{ppm}$ are assigned as the five sets of $\mathrm{CH}_{2}$ protons (labeled as $\mathrm{k}_{1-5}$ ) that arise from the n-hexanamide linker molecule at the DNP surfaces, which is similar to the reported chemical shifts of the $\mathrm{n}$-hexanamide molecule ${ }^{10}$. The second group of overlapped peaks at $3.50 \mathrm{ppm}$, $3.58 \mathrm{ppm}$ and $3.66 \mathrm{ppm}$ represent the eight $\mathrm{CH}_{2}$ protons with similar chemical environment that are attached on the TEPA chain (labeled as $1_{1-8}$ ), which are consistent with the chemical shifts from compounds that contains tetraethylenepentamine or polyamines ${ }^{11}$.

PAH-DNPs: Lastly, Figure 3e shows the ${ }^{1} \mathrm{H}-\mathrm{NMR}$ spectrum of the PAH-functionalized DNPs. Three broad peaks at $1.27 \mathrm{ppm}$ (labeled as n), $1.59 \mathrm{ppm}$ (labeled as o) and $2.67 \mathrm{ppm}$ (labeled as $\mathrm{m}$ ) correspond to three non-equivalent protons on the PAH polymer. We also assign these peaks based on previously reported research ${ }^{12-13}$ and labeled them as $\mathrm{m}, \mathrm{n}$ and o in Fig. 3e. The two sharp peaks labeled with an asterisk (*) in the PAH-DNPs at $1.9 \mathrm{ppm}$ and $3.8 \mathrm{ppm}$ come from residual ethanol used as a rinsing solvent during functionalization.

Table. S3. Quantitative ${ }^{1} \mathrm{H}-\mathrm{NMR}$ results of amino groups in the five cationic DNPs.

$\begin{array}{ccc}\text { Materials } & \begin{array}{c}\text { Quantified } \\ \text { species }\end{array} & \text { Stock concentration } \\ \mathrm{C} 3-\mathrm{NH}_{3}{ }^{+}-\mathrm{DNPs} & -\mathrm{NH}_{3}{ }^{+} /-\mathrm{NH}_{2} & 32.6 \mathrm{mM} \\ \mathrm{C} 3-\mathrm{N}\left(\mathrm{CH}_{3}\right)_{3}{ }^{+}-\mathrm{DNPs} & -\mathrm{N}\left(\mathrm{CH}_{3}\right)_{3}{ }^{+} & 29.5 \mathrm{mM} \\ \mathrm{C} 11-\mathrm{N}\left(\mathrm{CH}_{3}\right)_{3}{ }^{+}-\mathrm{DNPs} & -\mathrm{N}\left(\mathrm{CH}_{3}\right)_{3}{ }^{+} & 1 \mathrm{mM} \\ \text { TEPA-DNPs } & -\mathrm{NH}_{3}{ }^{+} /-\mathrm{NH}_{2} & \mathrm{mM} \\ \text { PAH-DNPs } & -\mathrm{NH}_{3}{ }^{+} /-\mathrm{NH}_{2} & 1.3 \mathrm{mM}\end{array}$


7. Biological responses plot versus diamond NP concentration. The DNP particle concentration was determined by gravimetric method. All weight measurements were done using an Electronic Semimicro, Micro, Precision and Analytical Balance (Sartorius Cubis Series, MSE Model). Premium Cover glass (Fisher Scientific, 18x18) was first measured without the samples. Then $10 \mu \mathrm{L}$ of sample was drop-casted onto the cover glass slide, dried overnight, exposed under ozone lamp to get rid of the organic ligand and was measured again. The final weight of the sample was determined by subtracting the weight of cover glass from the weight of cover glass plus sample. Each sample has three replicates and each measurement were repeated three times. The plot of biological response versus the diamond NP concentration (by weight) is shown in Figure S8.

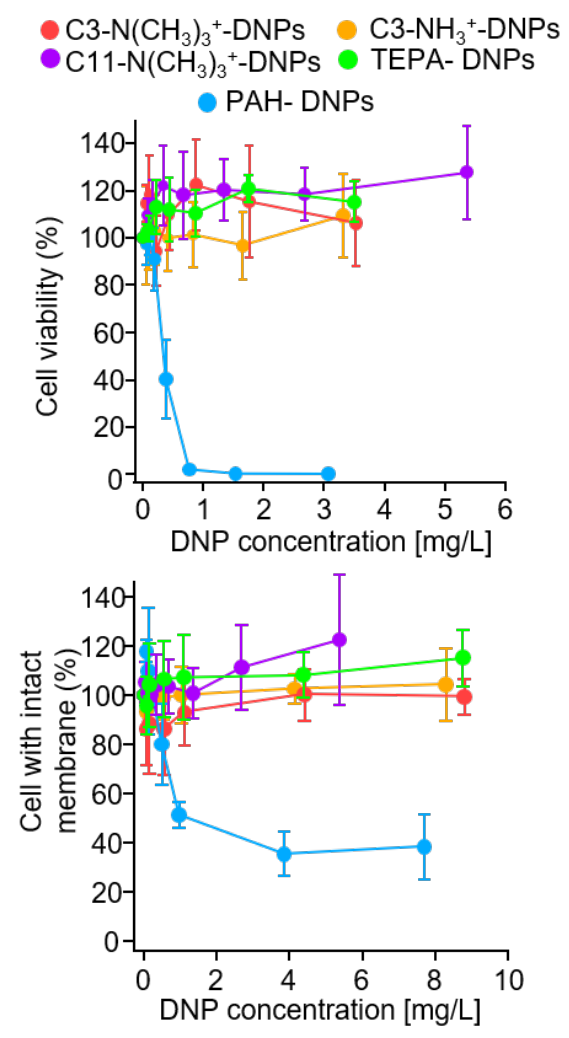

Fig. S8. (a) GBV and (b) L/D measurements versus the DNPs concentrations of the S. oneidensis. 
8. TEM micrographs of $S$. oneidensis before and after exposure to cationic-DNPs.

- TEM images of untreated healthy S. oneidensis.

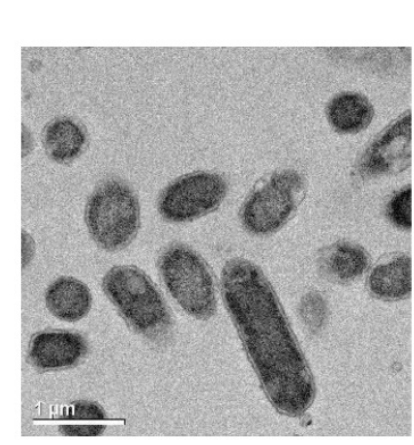

\section{Bright field}
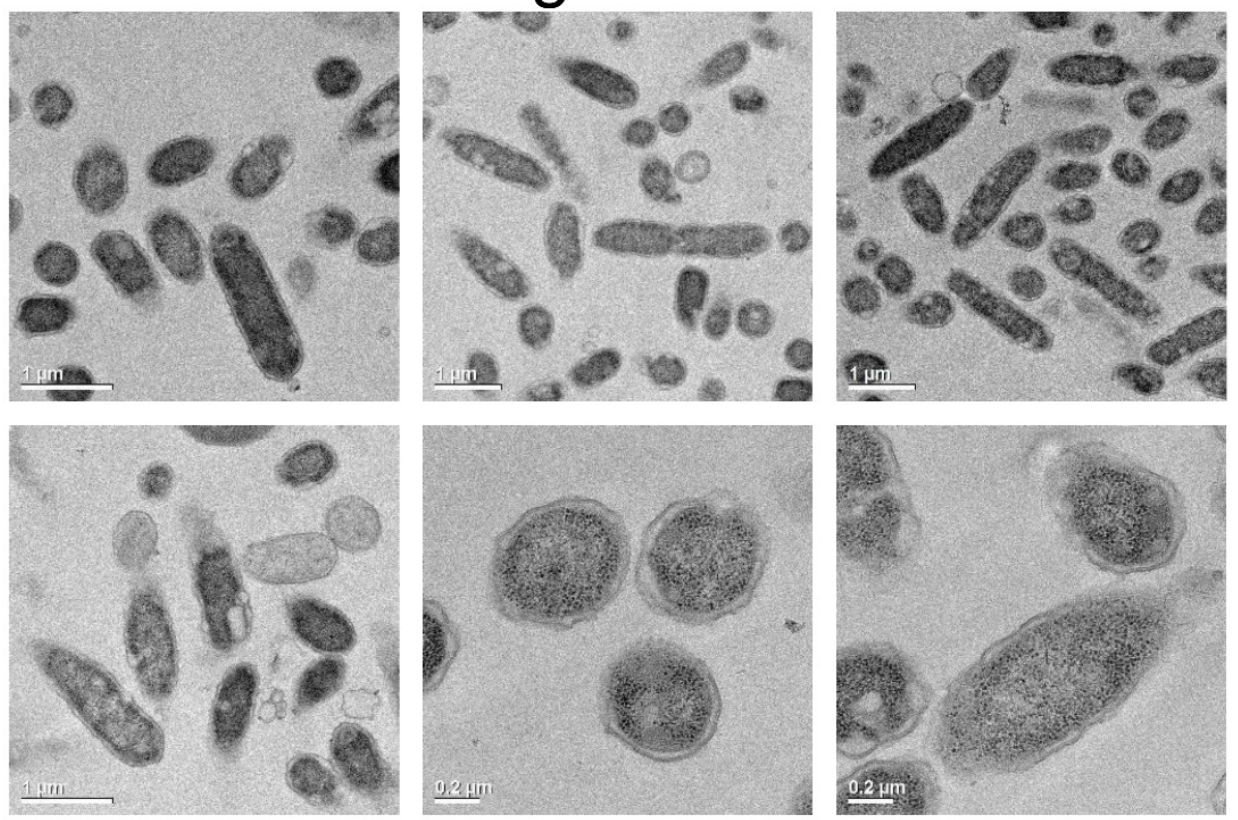

\section{Dark field}
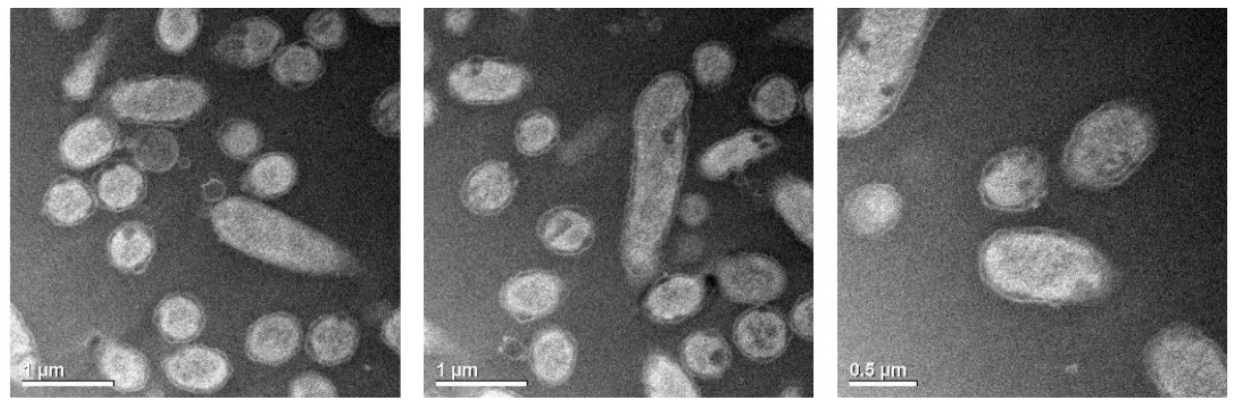
- TEM images of S. oneidensis exposed to DNPs functionalized with a linear ligand with terminal primary amine $\left(\mathrm{C} 3-\mathrm{NH}_{3}-\mathrm{DNPs}\right)$

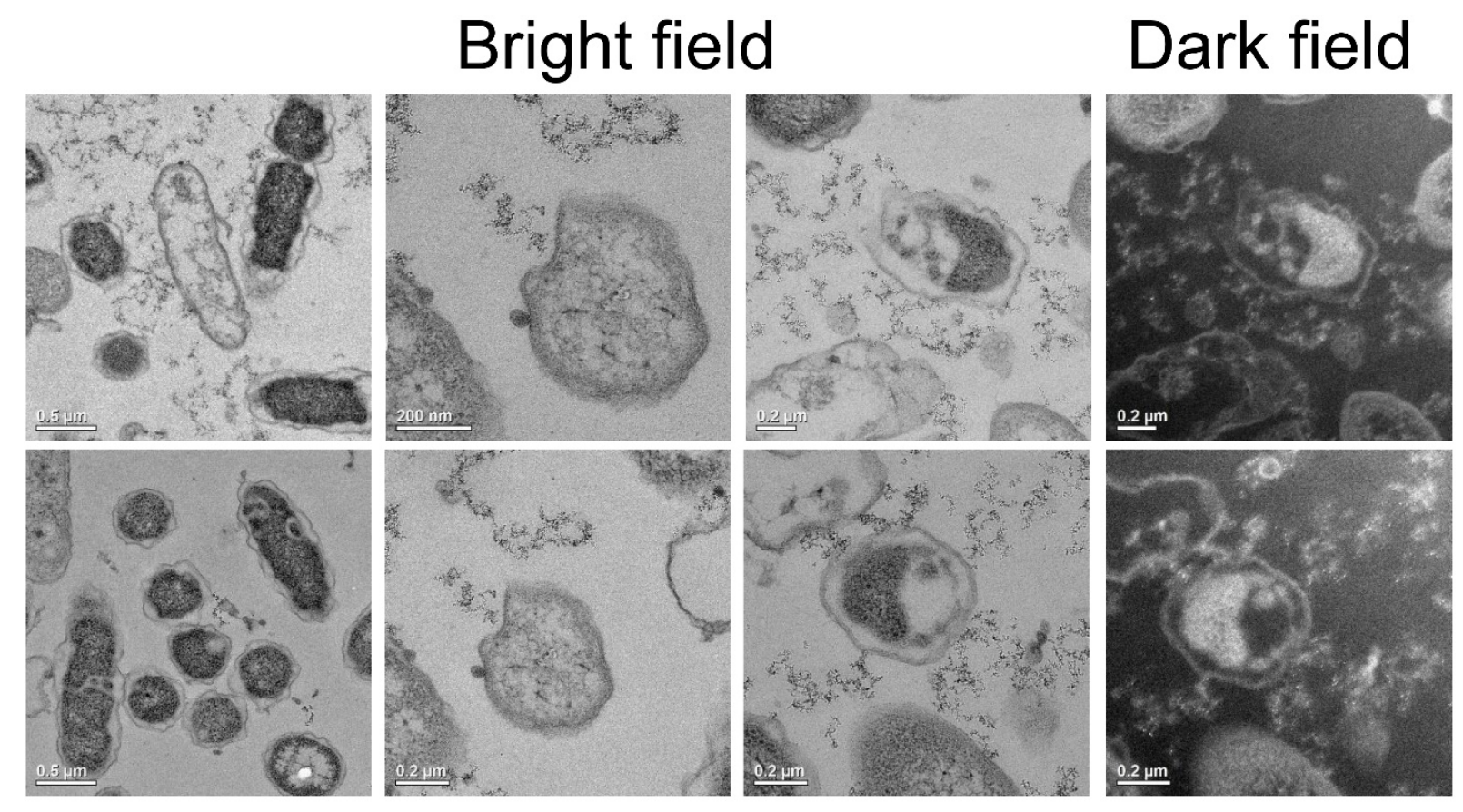


- TEM images of S. oneidensis that was exposed to polymer PAH functionalized DNPs.

\section{Bright field Dark field}
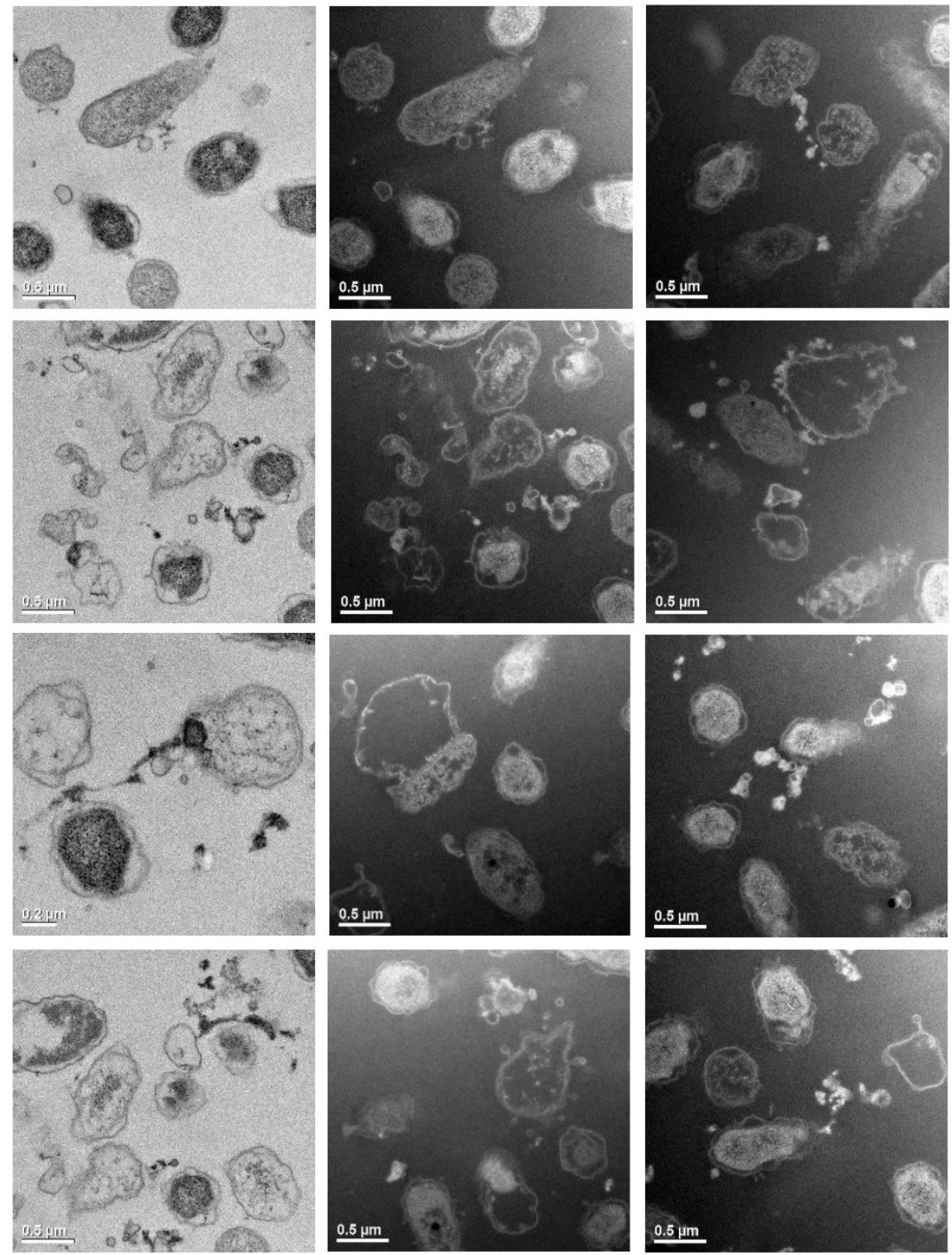


\section{References}

1. Vigderman, L.; Manna, P.; Zubarev, E. R., Quantitative replacement of cetyl trimethylammonium bromide by cationic thiol ligands on the surface of gold nanorods and their extremely large uptake by cancer cells. Angew. Chem. 2012, 124,660-665.

2. Strother, T.; Hamers, R. J.; Smith, L. M., Covalent attachment of oligodeoxyribonucleotides to amine-modified Si (001) surfaces. Nucleic Acids Res. 2000, 28,3535-3541.

3. Tanuma, S.; Powell, C. J.; Penn, D. R., Calculations of electron inelastic mean free paths. V. Data for 14 organic compounds over the 50-2000 eV range. Surf. Interfac. Anal. 1994, 21,165-176.

4. Torelli, M. D.; Putans, R. A.; Tan, Y.; Lohse, S. E.; Murphy, C. J.; Hamers, R. J., Quantitative determination of ligand densities on nanomaterials by X-ray photoelectron spectroscopy. ACS Appl. Mater. Intefac. 2015, 7,1720-1725.

5. $\quad$ Claridge, T. D., High-resolution NMR techniques in organic chemistry. Elsevier: 2016; Vol. 27.

6. Kunc, F.; Balhara, V.; Brinkmann, A.; Sun, Y.; Leek, D. M.; Johnston, L. J., Quantification and Stability Determination of Surface Amine Groups on Silica Nanoparticles Using Solution NMR. Anal. Chem. 2018, 90,1332213330.

7. Wu, M.; Vartanian, A. M.; Chong, G.; Pandiakumar, A. K.; Hamers, R. J.; Hernandez, R.; Murphy, C. J., Solution NMR analysis of ligand environment in quaternary ammonium-terminated self-assembled monolayers on gold nanoparticles: The effect of surface curvature and ligand structure. J. Am. Chem. Soc. 2019, 141,4316-4327.

8. Marbella, L. E.; Millstone, J. E., NMR techniques for noble metal nanoparticles. Chem. Mater. 2015, 27,27212739.

9. Zhang, Y.; Tamijani, A. A.; Taylor, M. E.; Zhi, B.; Haynes, C. L.; Mason, S. E.; Hamers, R. J., Molecular surface functionalization of carbon materials via radical-induced grafting of terminal alkenes. J. Am. Chem. Soc. 2019.

10. Abraham, R. J.; Mobli, M., Modelling 1H NMR spectra of organic compounds: theory, applications and NMR prediction software. John Wiley \& Sons: 2008.

11. Cornille, A.; Serres, J.; Michaud, G.; Simon, F.; Fouquay, S.; Boutevin, B.; Caillol, S., Syntheses of epoxyurethane polymers from isocyanate free oligo-polyhydroxyurethane. Europ. Poly. J. 2016, 75,175-189.

12. Qiu, T. A.; Torelli, M. D.; Vartanian, A. M.; Rackstraw, N. B.; Buchman, J. T.; Jacob, L. M.; Murphy, C. J.; Hamers, R. J.; Haynes, C. L., Quantification of free polyelectrolytes present in colloidal suspension, revealing a source of toxic responses for polyelectrolyte-wrapped gold nanoparticles. Anal. Chem. 2017, 89,1823-1830.

13. Zhang, Y.; Fry, C. G.; Pedersen, J. A.; Hamers, R. J., Dynamics and morphology of nanoparticle-linked polymers elucidated by nuclear magnetic resonance. Anal. Chem. 2017, 89,12399-12407. 